\title{
Analysis of Art Elements' Application in Clothing
}

\author{
Yanping Xie \\ Jiangxi Institute of Fashion Technology \\ Nanchang, Jiangxi, China 330201
}

\begin{abstract}
With the economic and political development as well as the gradual improvement of people's spiritual level, clothing design, as an essential part of packaging materials in people daily life, has shown its mental culture with each passing day. Especially in the era of art, clothing and art integrate each other more and more closely. The author of this paper has analyzed the art elements in clothing in detail through a lot of practice and research in this very context. The paper highlights the combination between clothing and art centering on spiritual cultural expression of clothing design, and make psychological analysis on several art elements in clothing such as the art of painting, art of calligraphy, art of sculpture, art of paper-cutting painting and art of matching with emphasis, to deeply analyze the relationship between it and clothing, explaining the supporting and complement role of art elements on clothing design, so as to increase the artistic charm to clothing and add dynamic sculpture to art.
\end{abstract}

Keywords—clothing; art elements; application; analysis

\section{INTRODUCTION}

The improvement of people's living standard makes the spiritual pursuit of clothing be more inclined to the abstract art level, and even extend to fuzzy direction. The evolution of the clothing spirit level driven by unpredictable art or the pattern makes an expression is a kind of art ideological trend of social development, becoming the symbol of spirit cultural packaging and driving people's soar in the field of spirit. As a branch of art design, clothing is increasingly revealing its economic role in terms of packaging humanistic spirit factors. Combine the elegance of clothing and the spiritual realm of artistic elements perfectly to give more mental language of clothing art to the customers. Thus it is favored by many consumers. As a result, art elements have become the focus of many designers immediately. On the stage of fashion, the clothing integrated with art elements has opened up the wonderful curtain, bringing us with the beautiful melody and wonderful music.

\section{Role OF PAINTING ART IN CLOTHING}

Clothing material is used for shaping the clothes, and pen and paper are used for painting. Although the two are not the same, the paper used for painting can be replaced with soft fabrics, becoming the carrier for painting, supporting the artistic and spiritual level of clothing, at the same time, giving dynamic display to the painting, becoming the smart kite in art. Now painting art element is widely used not only in clothing design, but the architecture, interior design, landscape design and automobile design also have the characteristics painting art. Every move of modern painting affects the clothing designers' inspiration motivation. Modern painting with abstract style is more close to the spiritual pursuit of clothing, and designers express brand new design thinking through the abstract painting art, with the combination of art language's external attractiveness with internal workmanship, to show the design connotation of clothing and the designer's ability.

There is a kind of interpenetrated relationship between clothing and art. Art is the source of inspiration and value enhancement as well as the ideological embodiment of economic development and social environment. Under the background of politics, the intricate and complex religious and political flavor is added, becoming the medium to extend and control the opinions of masses. Because of the restriction of religious color and style, the clothing under religious belief has restrained art a lot and restricted the development of art. However, religious art has added clean mental space to art due to purity of religious belief. The pattern design and color matching art in religious frescoes has brought about more inspiration for modern clothing, and its painting characteristics have become the objects pursued by designers. There are various classical painting art forms in China. Plant and animal painting as well as paintings of landscapes, birds and flowers present like mushrooms after rain. In the clothing design in recent years, animal design is developed under the love of cherishing natural environment and protecting animals, reflecting love and protection of animals. Plant flowers painting art has always been the art element used by designers. Printing apparel fabrics is also a bright spot in the international arena. Last year, the art element of classical ink paintings appeared in Chinese clothing works, and most of them take chiffon and silk fabrics for bottoming. There are printing and hand-painted patterns with strong humanity atmosphere, which is the complementing role between art and clothing economy.

\section{APPLICATION OF CALLIGRAPHY ART IN CLOTHING}

After thousand years' development, calligraphy art has formed the writing system with various characteristics. It is the essence of Chinese traditional culture and the crystallization of the wisdom of hardworking people. The integration of clothing and calligraphy art reflects the classic and elegant style of clothing and shows the classical aesthetic trend on the one hand. And on the other, it improves cultural awareness in clothing itself. Calligraphy contains profound cultural connotation, generally the trace of letters. Calligraphers express their inner thoughts as well as the understanding of art toward society using lines, pen and ink with rich spiritual attainment. There is common place between the design of dots and lines that constitute basic elements and the line design of 
calligraphy. So integrate calligraphy element into clothing design is the combination design of elements, which is a kind of pattern development.

The application of calligraphy element in modern clothing design is mainly to decorate the clothing reflecting classical style. The fabric of clothing with stand collar and plate buttons as the main characteristics takes silk and cotton as carrier, and cooperate with calligraphy font or the expression of line, curved or straight, folding or unfolding, and fabric texture effect, straight or fold, or loose template design, these are combined together naturally, deducing Oriental temperament that stresses meek and humble. Calligraphy element and character patterning are used in most of modern Chinese costume design. Transform the calligraphy lines to meet classic personality design requirements, cooperate with the structure and profile of Chinese costume, forming a unique clothing flavor. Generally, the clothing packaged by calligraphy is quiet and elegant, to foil the environment and raise the dress quality. The application of calligraphy element in clothing is the sublimation of art, and also the integration of artistic essence and life, the combination of classical and modern, and the fusion of pure art and practical art. Calligraphy not only exists in the clothing design, but also exists in the home textile fabric design and wallpaper graphic design. Then the spiritual culture spreads over the entire room with strong artistic atmosphere. As a kind of dynamic packaging, clothing is inheriting thousands of years of Chinese cultural essence together with calligraphy.

\section{ApPlicAtion OF SCUlPture ART IN ClOTHING}

Modern clothing represents a kind of silent language. We can only observe and feel its artistic charm through eyes. Visuality is the characteristic of modern clothing. All aspects of clothing are connected with everything of life. The combination of sculpture art and clothing reflects the elaborate manufacturing process of clothing, which is the result of hard work. With positive mental energy gathered in clothing, great spiritual connotation is given to the clothing.

Clothing is regarded by many designers as "soft sculpture". The author has been engaged in clothing design for many years, thinking that there is a deep origin between clothing and sculpture art. Sculpture is the sculpting and shaping process through physical things, while the material used by clothing is soft fabrics, which will be finally put on human body after pattern making, cutting and stitching. Clothing design process is the sculpting and shaping process of human body. The process of clothing sculpture is to make there are more modeling beauty and structure beauty between clothing material and human body by virtue of sculpture technique. Throughout the international brand clothing press conference, many have adopted the exquisite sculpture technique to create external modeling beauty of clothing. Although the fabric used for clothes is soft, the good reputation of "soft sculpture" brought by it to clothing is self-evident in combination with human body's supporting effect.

\section{APPLiCATION OF PAPER-CUTTING ART IN CLOTHING}

Paper-cutting art is China's intangible cultural heritage, and its cultural connotation and concept have a far-reaching influence. Paper-cutting is widely used in clothing, which has made the paper-cutting art that stays in plane presentation base be grafted to the three-dimensional human body, presenting the application of paper-cutting using three-dimensional image. This is the effect of complementing each other by the two factors. The integration of clothing design and paper-cutting design makes the clothing be of more ethnic and local characteristics. In the field of personalized clothing design, paper-cutting art is of high design value. Paper-cutting art is a kind of traditional culture, but also the traditional culture closed related to people's customs, beliefs and emotion. Along with the development of the era, paper-cutting art is increasing combined with the production and living of people. The combination of paper-cutting art and clothing mostly adopts the techniques such as hollowing, collage and cutting. Such reference is the inheritance and development of traditional manual technology, which is also the manifestation of cultural heritage serving the public.

Hollowing technology in paper-cutting is mostly used to conduct hollowing processing to fabric in clothing and increase individualization of clothing fabrics. The simplest clothing hollowing design is the hollowing of various patterns, to increase new technique for pattern design. The hollowing pattern is the design of key parts, and then it develops to the hollowing of the whole dress, forming the invisible intention, adding mystique and visual impact to the clothing. Modern clothing pays more attention to detail design. The hollowing technique in paper-cutting art is the secondary development of fabrics. It not just expresses the charm and sexuality, but also pays more attention to the wearers' spiritual appearance and cultural appeal. The application of collage takes the effect of three-dimensional relief as the main way of expression. Upon the completion of fabrics' hollowing design, stick it at the expression position, to increase the thickness of clothing fabrics, rendering the significance of three-dimensional sculpture. As for heavy fabrics, carving pattern can be adopted to complete clothing design. Integrating paper-cutting elements into clothing to form clothing art works can increase the clothing's value, and it also has carried on the extensive and profound traditional culture.

\section{APPLICATION OF SPLICING ART IN CLOTHING}

In recent years, the innovative application of clothing materials and clothing color has brought back many clothing design techniques to life. As the classical clothing design technique, although splicing has always been active in the design stage, with the fashion popularity trend, it has become the most important design technique, affecting people's aesthetic trend gradually. The modern clothing materials change with each passing day, and the development of new materials needs shorter time, facilitating clothing design greatly. Differences exist in fabric thickness, function, appearance, and pattern. As a result, while splicing the fabrics, we shall consider the differences between fabrics, and try to narrow the difference, so the splicing would make the dress more perfect. In recent years, the popular thin splicing fabrics 
include organza fabric, lace fabrics, silk fabrics, etc., the splicing of them with the winter woolen or down feather fabric will increase the mysterious and visual beautiful effect on the one hand, and on the other, it reflects clothing aesthetic trends and the charm of splicing art. Color splicing cannot be separated from the differences between fabrics, and it directly affects the appearance of dresses. The splicing of fabrics with same color is mostly the splicing of structure, and splicing of different fabrics with different colors makes the overall clothing alive, which can be abstract and generous, elegant and classic, high-end and fashionable. In the trend of popular bright color in clothing, the collision of bright colors forms the color collision splicing, which is also a kind of fashion in clothing, reflecting that the life of people can collide out many beautiful sparks, and it is the external visual representation of consumer's inner charm.

Splicing art also has the structure splicing, which is to make the dress fit the wearer better. As for the close-fitting clothes, more attention shall be paid to the line saving splicing at structure position. No matter what the splicing way is, as a kind of clothing design element, splicing art is giving play to its charm of artistic cultivation and enriching the lives of consumers.

The above is the analysis of artistic elements that are commonly used in clothing. There are still many artistic elements in clothing design, such as illustration art, embroidery art and so on, which haven't been analyzed in this paper. The author expects to analyze the influence on clothing by artistic elements in future research. Generally speaking, clothing is a kind of art, adding artistic elements into it is the artistic shaping of visual modeling, and a kind of concept and technique of clothing design. The formation of artistic elements has long history and unique design thinking. Clothing design contains the art forms with rich cultural connotation, which is the embodiment of the integration of clothing and spiritual culture.

\section{REFERENCES}

[1] Meng Juan. Discussion on Infiltration into Clothing Design by Painting Art. MODERN SILK SCIENCE \& TECHNOLOGY, 2015-12.

[2] Wen Yufan. Research on Application of Chinese Ink Painting in Clothing Design. Northeast Normal University, 2015-06-01.

[3] Sheng Hui. Enlightenment on Clothing Design by Calligraphic Art. Qufu Normal University, 2014-03-01.

[4] Kong Xiangmei, Liang Qing. Discussion on Formal Beauty of Clothing Decorative Sculpture. Journal of Northeast Dianli University, 2012-12.

[5] Li Changiiang. Application of Paper-cutting Art in Modern Clothing Design. Harbin Normal University, 2014-06-01.

[6] Hu Yabing. Application of Paper-cutting Art in Clothing Design. Neijiang Technology Art, 2007-05-25.

[7] Ke Yudan. Application of Splicing Art in Clothing Design. Art Panorama, 2014-11-15. 